$\frac{\text { PNL-2276 }}{\text { UC-41 }}$

\title{
The Hanford Critical Radiation Dosimeter
}

November 1977

Prepared for the

U.S. Department of Energy

under Contract EY-76-C-06-1830

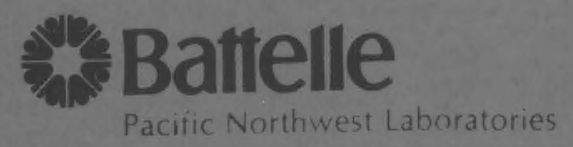




\title{
NOTICE
}

This report was prepared as an account of work sponsored by the United States Government. Neither the United States nor the Department of Energy, nor any of their employees, nor any of their contractors, subcontractors, or their employees, makes any warranty, express or implied, or assumes any legal liability or responsibility for the accuracy, completeness or usefulness of any information, apparatus, product or process disclosed, or represents that its use would not infringe privately owned rights.

The views, opinions and conclusions contained in this report are those of the contractor and do not necessarily represent those of the United States Government or the United States Department of Energy.

\author{
PACIFIC NORTHWEST LABORATORY \\ operated by \\ BATTELLE \\ for the \\ UNITED STATES DEPARTMENT OF ENERGY \\ Under Contract EY-76-C-06-1830
}

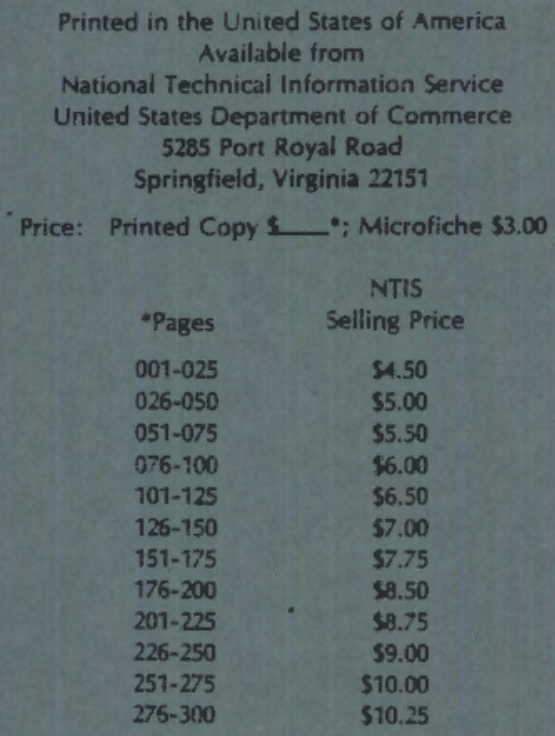




\section{1}

PNL-2276

UC-41

THE HANFORD CRITICAL

RADIATION DOSIMETER

by

R. D. Glenn

P. E. Bramson

November 1977

BATTELLE

Pacific Northwest Laboratories

Richland, Washington 99352 


\section{CONTENTS}

$\begin{array}{lr}\text { INTRODUCTION } & 1 \\ \text { COMPONENT IDENTIFICATION } & 2 \\ \text { DOSE MEASUREMENT } & 3 \\ \text { NEUTRON SPECTRUM MEASUREMENT } & 10 \\ \text { ENERGY RANGE, } 0.025 \text { to } 0.3 \mathrm{eV} & 10 \\ \text { ENERGY RANGE, } 0.3 \text { to } 2 \mathrm{eV} & 12 \\ \text { ENERGY RANGE, } 2 \mathrm{eV} \text { to } 1 \mathrm{MeV} & 14 \\ \text { ENERGY RANGE, } 1 \text { to } 2.9 \mathrm{MeV} & 15 \\ \text { ENERGY RANGE, AbOVe } 2.9 \mathrm{MeV} & 15 \\ \text { GAMMA DOSIMETRY } & 17 \\ \text { SUMMARY AND CONCLUSIONS } & 18 \\ \text { REFERENCES } & 20\end{array}$



THE HANFORD CRITICAL RADIATION DOSIMETER

\section{INTRODUCTION}

The Hanford critical radiation dosimeter, developed by Bramson ${ }^{(1)}$ for measuring neutron dose and spectrum distribution from nuclear radiation, has been modified to incorporate new dosimetry techniques and to correct assembly errors. Modifications to the dosimeter package are 1) inclusion of ${ }^{6} \mathrm{LiF}$ and ${ }^{7}$ LiF thermoluminescent dosimeter (TLD) chips in the foil holder at the lower end of the dosimeter "candle" for measurement of neutron and gamma dose, 2) removal of the indium foil in the foil holder at the lower end of the dosimeter candle, to reduce gamma dose to the TLD chips due to activation of the indium foil, 3) inclusion of a ${ }^{7}$ LiF TLO chip for measuring gamma dose and removal of glass rod dosimeters from the foil holder at the top of the dosimeter candle, and 4) correction of an assembly error by moving the copper foil inside the cadmium shields. Neutron spectrum measurements will still yield five energy groups, and the dose measurement will give the single-collision neutron dose over a wide range of neutron energies with an accuracy of $\pm 15 \%$ with in the range of a few rads to several thousand rads. Measurement of gamma dose between 0.1 and 10,000 rads is provided by the ${ }^{7}$ LiF TLD chips placed in the top and bottom of the dosimeter candle. 


\section{COMPONENT IDENTIFICATION}

The components of the Hanford critical radiation dosimeter and their locations are identified as follows:

- Gold Foils

No. 1 - in the foil holder at the bottom of the dosimeter candle No. 2 - outside the cadmium shields in the foil holder at the top of the dosimeter candle

No. 3 - inside the cadmium shields in the foil holder at the top of the dosimeter candle

- Indium Foils

No. 1 - removed from dosimeter

No. 2 - outside the cadmium shields in the foil holder at the top of the dosimeter candie

No. 3 - inside the cadmium shields in the foil holder at the top of the dosimeter candie

- Copper Foil

inside the cadmium shields in the foil holder at the top of the dosimeter candle

- Sulfur Pellet

outside the cadmium shields in the foil holder at the top of the dosimeter candle

- TLD Chips

No. 1 - one ${ }^{7}$ LiF chip in a gelatin capsule in the foil holder at the top of the dosimeter candle

No. 2 - one ${ }^{6}$ LiF chip (wrapped in red tin foil) and one ${ }^{7}$ LiF chip (wrapped in green tin foil) in the foil holder at the bottom of the dosimeter candle 


\section{DOSE MEASUREMENT}

The theory for the development of the Hanford critical. radiation dosimeter is simple. When a neutron engages in scattering collisions with the atoms of a hydrogenous material, it is degraded in energy. After the first, second, or nth collision, there is a probability that the neutron has been degraded to the thermal energy range where it can be readily captured by a slow neutron absorber such as gold, cadmium, or ${ }^{6}$ LiF. Many of the neutrons entering the moderator will be captured in the moderator; others will scatter back out, travel through without incident, or otherwise escape capture in the detector medium.

The rate at which neutrons slow down in a moderating material is a function of the neutron energy and the moderator scatter cross section. Therefore, the capture of neutrons by a detector medium surrounded by a given thickness of moderator is a function of the slowing down rate in the moderator and the capture cross section of the detector over the entire spectrum of neutron energies involved.

DePangher ${ }^{(2)}$ investigated the response of a $\mathrm{BF}_{3}$ tube with respect to paraffin moderator thickness and initial neutron energy. He found that a paraffin thickness of 4-1/2 in. resulted in the optimum condition in which $\mathrm{BF}_{3}$ counts per unit dose were fairly constant for neutron energies from $150 \mathrm{keV}$ to about $6 \mathrm{MeV}$ (Figure 1). Proceeding on the basis of DePangher's results, the paraffin-moderated criticality dosimeter was designed as described in the following paragraph.

The paraffin moderator used for the Hanford critical radiation dosimeter is $9-1 / 8$ in. long by $9-1 / 8$ in. in dia with $4-i n$.-thick walls (Figure 2). The moderator is equipped with a l-in.-dia polyethylene "candle" and aluminum foil holder inserts. A $1-\mathrm{cm}$ by $1-\mathrm{cm}$ by $0.005-\mathrm{in}$. gold foil and a set of ${ }_{\mathrm{LiF}}$ and ${ }^{7}$ LiF TLD chips are mounted in the lower end of the polyethylene candle. When in place in the dosimeter, the gold foil and TLD chips are positioned approximately at the geometrical center of the moderator. 


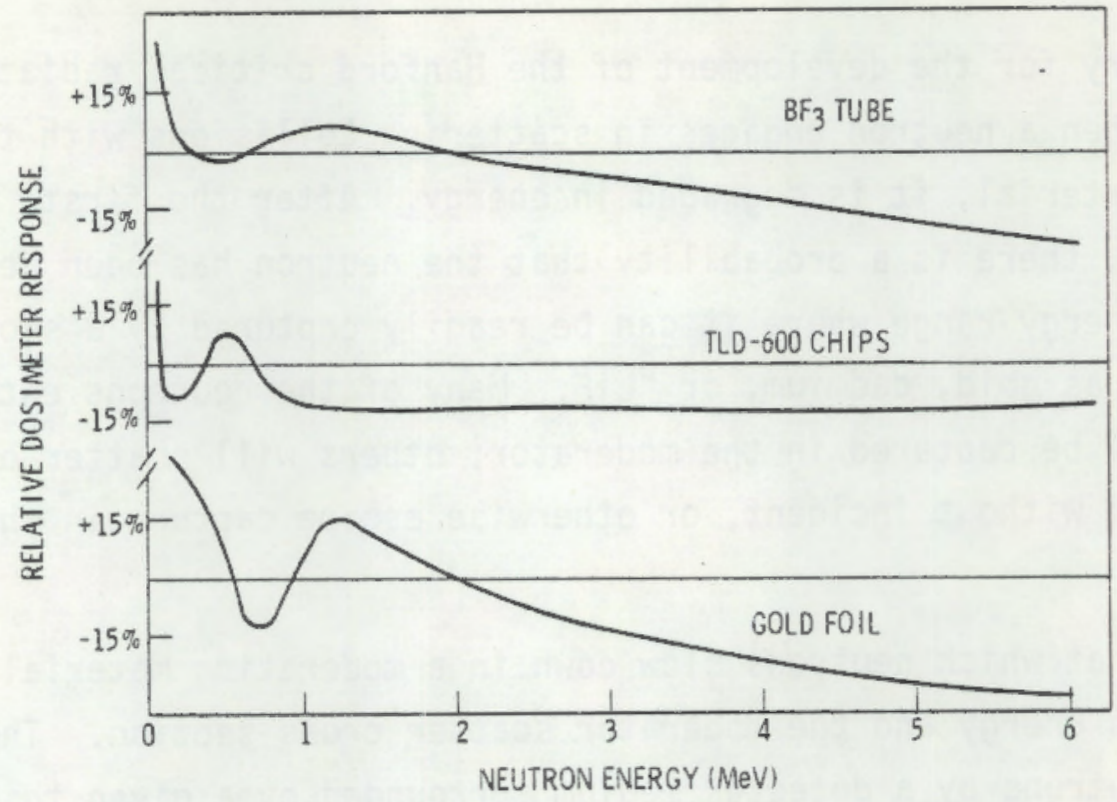

FIGURE 1. Energy Response of Hanford Critical Radiation Dosimeter

Calculation of the single collision neutron dose can be accomplished either by gold foil activiation counting or by reading the TLD chips. The two methods of calculating dose were cross-calibrated using ${ }^{235} U$ fission spectra neutrons.

Elementary gold is $100 \%{ }^{197} \mathrm{Au}$, which has a $98-b$ thermal neutron absorption cross section and a 15,000-b resonance absorption at $4.9 \mathrm{eV}$. Calibration of the moderated gold foil over the $55-\mathrm{keV}$ to $7-\mathrm{MeV}$ neutron energy response of the dosimeter using the gold foil is shown in Figure 1.

The TLD system used in the Hanford critical radiation dosimeter requires the use of two types of dosimeter chips, ${ }^{6}$ LiF and ${ }^{7}$ LiF. The ${ }^{6}$ LiF chip is sensitive to beta radiation, gamma radiation, and thermal neutron radiation while the ' LiF chip is sensitive to beta and gamma radiation. The difference between the two types of dosimeter chips is equal to the neutron dose in rads as calculated by Equation (1):

$$
\text { Dose }=\left[{ }^{6} \text { LiF }-\left(0.84^{7} \text { LiF }\right)\right]\left(3 \times 10^{-5}\right)
$$




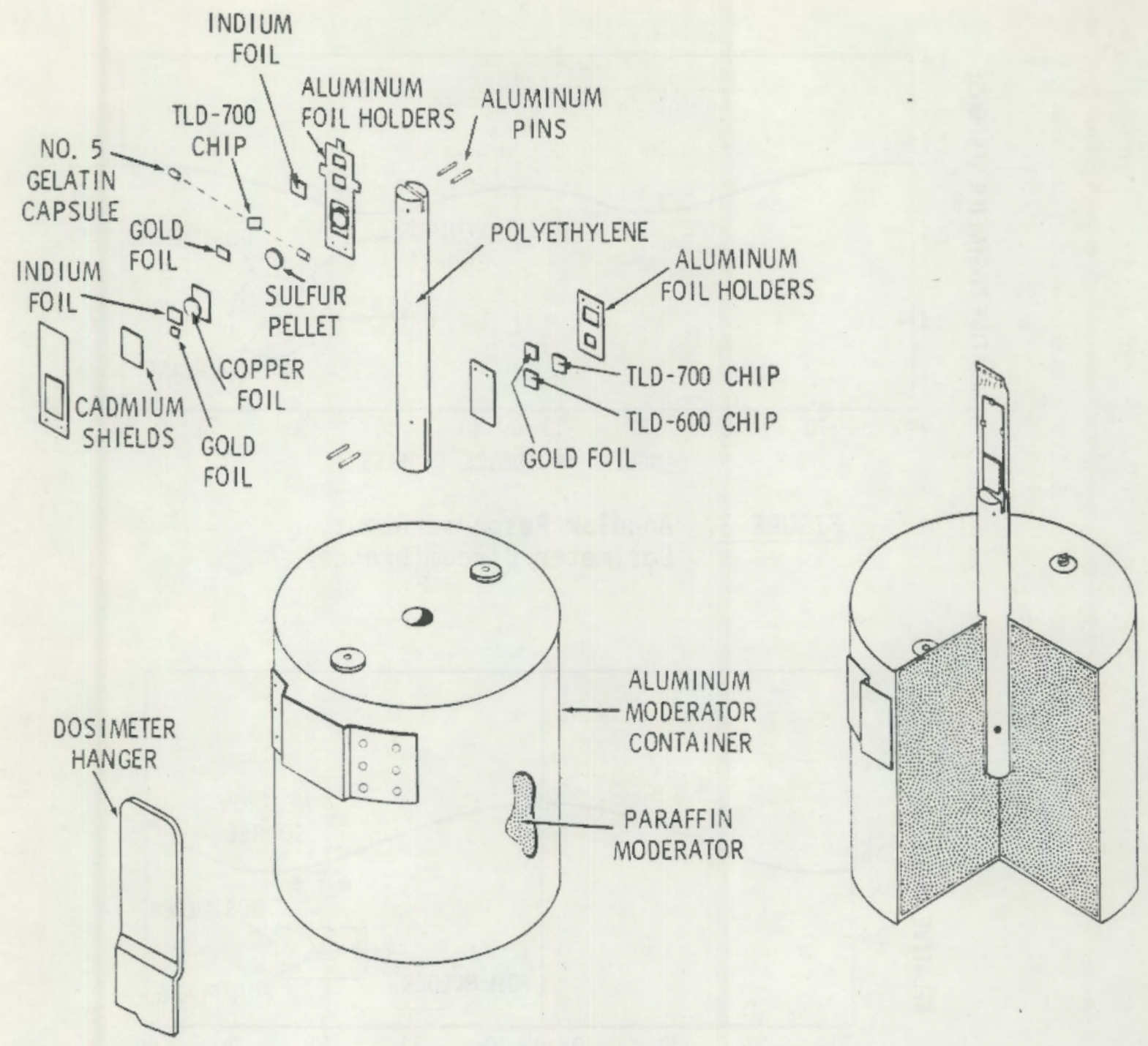

FIGURE 2. Hanford Critical Radiation Dosimeter

Angular dependence of the moderated foil dosimeter for various angles about the circumference was studied. Figure 3 shows the response of the dosimeter at various angles with respect to the foil plane and normalized to the response at $90^{\circ}$. The overall variation of about $\pm 10 \%$ is due to the fact that the gold foils and TLD chips are too large to act as point detectors. The variation of response at angles with the dosimeter axis is shown in Figure 4. Generally, the angular response will not be a problem. The dosimeter is to be used in fixed locations, with exact placement based on speculation as to the most probable location of a nuclear radiation release. 


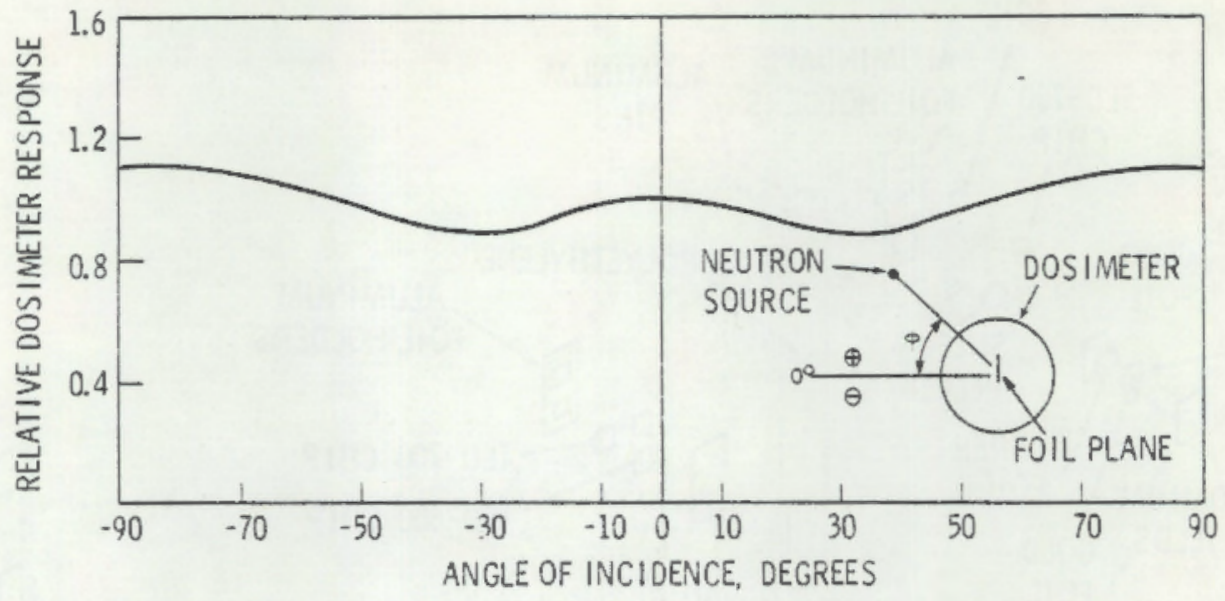

FIGURE 3. Angular Response About

Dosimeter Circumference

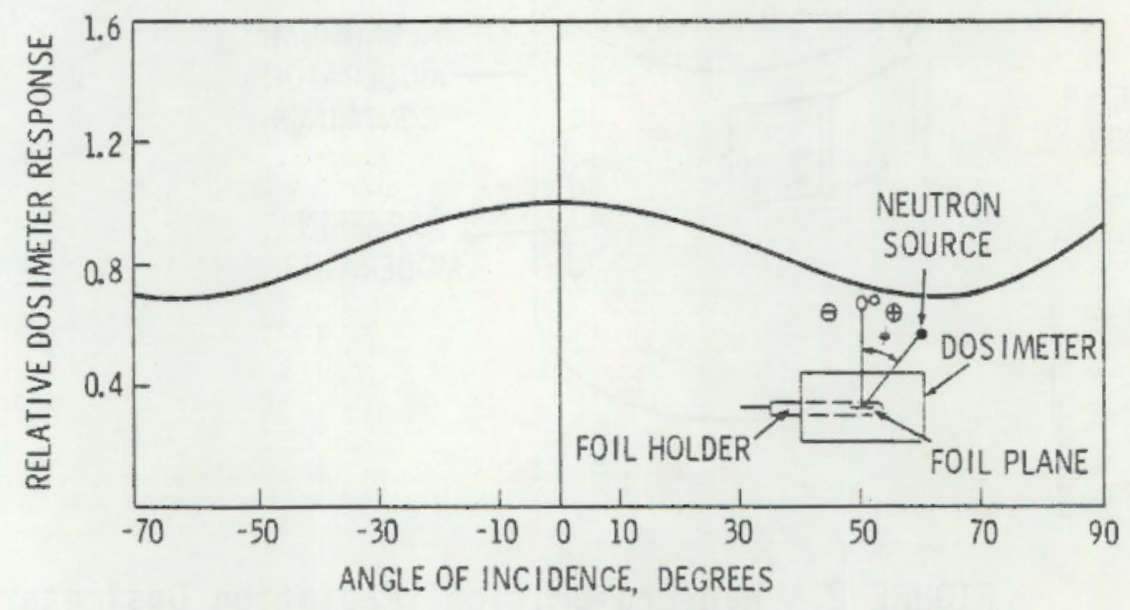

FIGURE 4. Angular Response About Dosimeter Axis

The height of placement above the floor and associated angles are thus controlled. Corrections can be made for angular displacement of the radiation source since the exact location of the source can be established. The angle of incidence for room-scattered neutrons, however, cannot be corrected. 
Neutrons with energy less than $100 \mathrm{keV}$ cause error in the dosimeter operation. The response to neutrons of $55 \mathrm{keV}$ is nearly double the average response to $100 \mathrm{keV}$ or greater. The response to energies less than $55 \mathrm{keV}$ has not been investigated because of the unavailability of such low-energy sources. The result of the high sensitivity of the dosimeter for low-energy neutrons is an overestimation of the neutron dose from those energies. The overall effect may, in. practice, balance out because the dose from neutrons above $2 \mathrm{MeV}$ is underestimated, as Figure 1 indicates.

An example of the quality of performance that can be expected from the dosimeter may be of value at this point. Figure 5 shows the neutron energy spectra of several neutron sources, ${ }^{(3)}$ including the theoretical ${ }^{235} \mathrm{U}$ fission neutron spectrum ${ }^{(4)}$ and the Godiva II leakage neutron spectrum. ${ }^{(5)}$ The response of the moderated foil dosimeter to these two spectra is of particular value because the spectra are typical of the neutron energy spectrum that could be encountered in an actual exposure to neutrons from fissioning material.

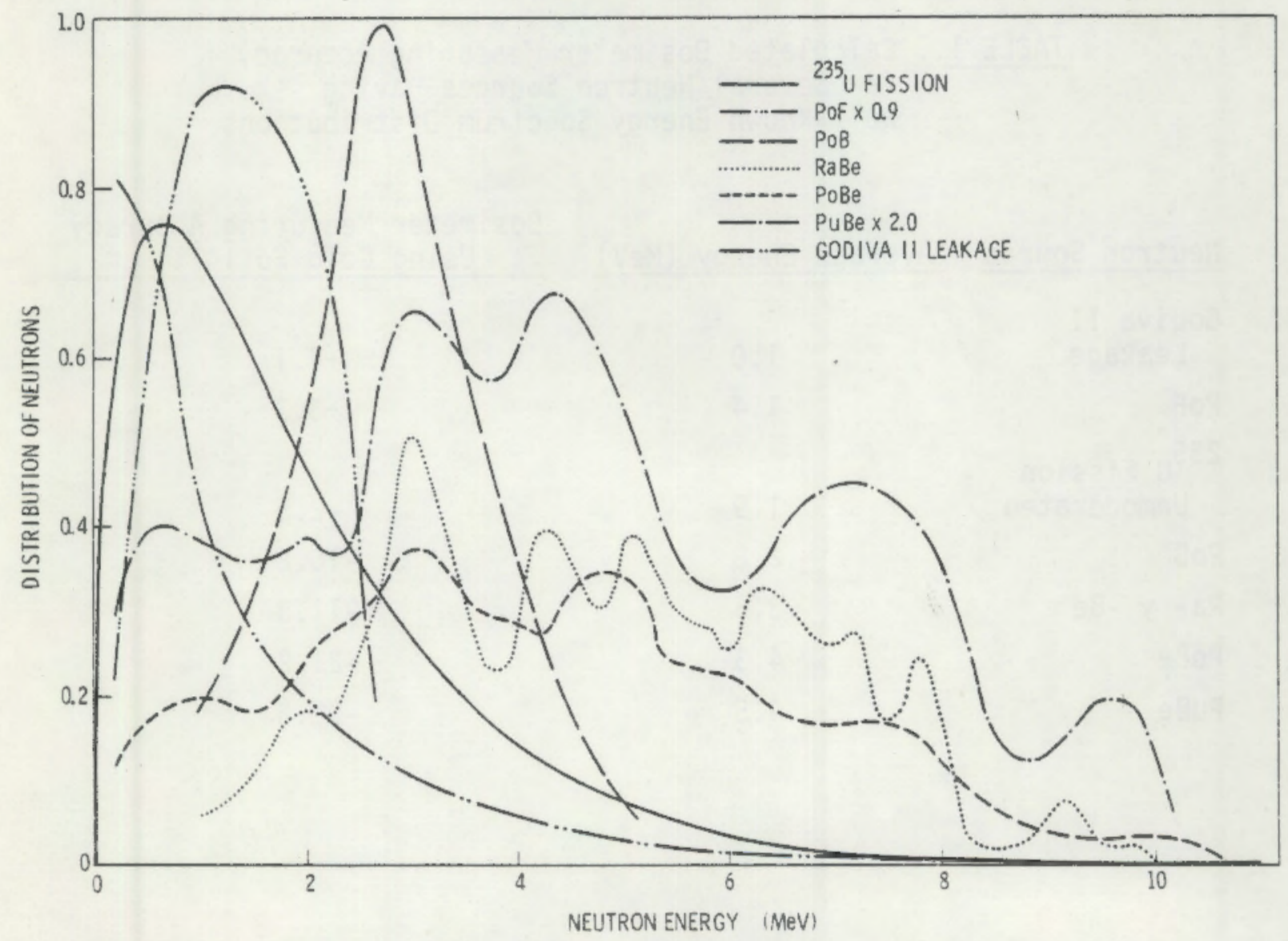

FIGURE 5. Energy Spectra of Various Neutron Sources 
The data in Table 1 give the calculated overall accuracy with which a dose of neutrons would be measured if the neutron spectrum involved were that of the neutron source indicated. The data are based on the gold foit energy response curves of Figure 1 using a 56-group energy breakdown from thermal to $11 \mathrm{MeV}$, i.e., neutron groups with a 200-keV energy spread. For the unmoderated ${ }^{235} \mathrm{U}$ fission spectrum, the neutrons below $150 \mathrm{keV}$ are only $2.4 \%$ of the total flux and amount to only $0.5 \%$ of the maximum single-collision theory exposure ${ }^{(6)}$ that would be imparted to tissue. These neutrons could, therefore, be measured with a tenfold oversensitivity and still cause only a $5 \%$ measuring error. For the calculations in Table 1, it was assumed that the therma 7 - to $200-k e V$ group dose overestimation was $>500 \%$ for gold.

The expected response of ${ }^{6} \mathrm{LiF}$ dosimeter chips will approximate gold foi? response. This assumption is based on the fact that both detectors approximate a $1 / r$ detector and both are located in the center of a 9-in. polyethylene cylinder. For comparison, a plot of the response of ${ }^{6} \mathrm{LiF}$ dosimeter chips ${ }^{(7)}$ is included in Figure 1.

TABLE 1. Calculated Dosimeter Measuring Accuracy for Several Neutron Sources Having We11-known Energy Spectrum Distributions

$\begin{array}{lcc}\text { Neutron Source } & \text { Average Energy (MeV) } & \begin{array}{c}\text { Dosimeter Measuring Accuracy } \\ \text { Using Gold Foi }(\%)\end{array} \\ \begin{array}{l}\text { Godiva II } \\ \text { Leakage }\end{array} & 1.0 & \\ \text { PoF } & 1.4 & +4.1 \\ 235_{\text {U Fission }} & & +3.7 \\ \text { Unmoderated } & 1.9 & -2.5 \\ \text { PoB } & 2.8 & -10.8 \\ \text { Ra- } \gamma-B e & 3.6 & -11.3 \\ \text { PoBe } & 4.3 & -21.2 \\ \text { PuBe } & 4.5 & -22.6\end{array}$


The useful dose measuring range of the dosimeter is nearly unlimited for instantaneous or short-duration (i.e., several minutes) neutron exposure. The lowest neutron exposure measured during the calibration study was about 5 mrads. The only upper limits would be: 1) saturation of the dosimeter foils which, for short duration exposures, would require a flux on the order of $10^{16} \mathrm{n}-\mathrm{cm}^{-2}-\mathrm{sec}^{-1}$ or about $10^{6} \mathrm{rads} / \mathrm{sec}$ at the dosimeter position, and 2) too high a decay count rate to be counted without jamming the counting equipment. The first of these two possible limits will probably never be a problem unless the irradiation duration approaches or exceeds the half life of the radioactive product. The second situation can easily be adjusted for by waiting to count the foil until the activity has decayed to a level low enough so that the counting equipment can handle it. The use of suitable shielding between the sample and detector during counting will also compensate for too high a count rate.

Table 2 gives the equations for calculating neutron exposure.

TABLE 2. Equations for Calculating Neutron Exposure Dose Using Hanford Critical Radiation Dosimeter

$$
\begin{aligned}
& \text { TLD Dose (rads) }=\left[{ }^{6} \text { LiF }-\left(0.84^{7} \mathrm{LiF}\right)\right]\left(3 \times 10^{-5}\right) \\
& \begin{aligned}
\text { Gold Foil Dose (rads) } & =\frac{\text { dis (min-g) })^{-1} \text { for gold foil }}{21 \text { dis }(\text { min-g-mrad })^{-1}} \\
& =\text { Neutron Dose } \pm 15 \%
\end{aligned}
\end{aligned}
$$




\section{NEUTRON SPECTRUM MEASUREMENT}

The spectral distribution of the neutron fluence associated with a neutron exposure is of interest as well as the intensity. The best means available for determining the neutron spectrum is to observe the radioactivity of certain chemical elements after exposure to the neutron fluence.

The chemical elements useful in measuring a neutron spectrum should have one of two neutron cross-sectional characteristics. The element should have either a fairly constant activation cross section over a wide energy range, or a much greater activation cross section for a particular range of neutron energies than for most other energies. Although a number of elements have the necessary activation characteristics, only a few may be combined into a group to give accurate measurements over a wide energy range. The elements selected for use in this dosimeter application are indium, gold, copper, sulfur, and cadmium. The combination of these elements in a dosimeter unit is commonly used.

The end of the polyethylene candle, which extends out of the dosimeter about 4 in., is fitted with an aiuminum foil holder (Figure 2). The holder is designed to accommodate two $5 / 8$ - by $1 / 2$ - by $0.010-i n$.-thick indium foils, two $1-\mathrm{cm}$ by $1-\mathrm{cm}$ by $0.005-$ in. -thick gold foils, two $7 / 8-$ by $1-1 / 4-$ by 0.040 -in . cadmium shields, one 7/8-in.-dia by 0.085-in.-thick sulfur pellet, and one 7/8-in.-dia by 0.008-in.-thick copper foil. These elements, when subjected to neutron radiation, become radioactive by various neutron-induced processes due primarily to particular portions of the neutron energy spectrum. A mathematical manipulation of the data obtained from counting the radioactivity of the foils will result in a division of the neutron spectrum into the five energy groups discussed in the following paragraphs.

ENERGY RANGE, 0.025 to $0.3 \mathrm{eV}$

Indium-115 has a thermal neutron activation cross section of $145 \mathrm{~b}$ and is assumed to be constant throughout the thermal region up to $0.3 \mathrm{eV}$. Cadmium has a 3300-b thermal absorption cross section and if thick enough ( $0.020 \mathrm{in}$.) will effectively absorb all neutrons with energy less than $0.3 \mathrm{eV}$. An indium 
foil shielded with $0.040-i n$. cadmium will, therefore, become activated by neutrons above $0.3 \mathrm{eV}$ and primarily by neutrons of about 1.4-eV energy because of the 28,000-b resonance absorption at $1.4 \mathrm{eV}$. The difference in activation between a bare indium foil and nearly identical 0.040-in. cadmium-shielded indium foil is, therefore, due to neutrons in the $0.025 \mathrm{-eV}$ to $0.3-\mathrm{eV}$ energy range. A correction factor of $1.17^{(8)}$ must be used with the activation value for cadmium-shielded indium to correct for absorption of resonance neutrons by the cadmium.

The equation for determination of thermal neutron fluence $\left(\emptyset_{t}\right)$ is

$$
\emptyset_{t}=\frac{\left[\text { dis }(\text { min-g })^{-1} \text { for bare } \text { In }\right]-\left[1.17 \times \text { dis }(\text { min-g })^{-1} \text { for } c d-\right.\text { shielded In] }}{C_{1} c}=n v
$$

where

$$
\begin{aligned}
\operatorname{dis}(\min -g)^{-1}= & \text { activation value corrected for background, counting geometry, } \\
& \text { and decay before counting } \\
c_{1}= & 1.06 \times 10^{-2} \text { dis }(\text { min }-g-n v)^{-1} \\
c= & \text { backscatter coefficient for material against which the dosi- } \\
& \text { meter is mounted }(9)(\text { air, } 1.0 \text {; human body, } 2.0 \text {; stainless } \\
& \text { steel, } 1.4 \text {; concrete, } 1.6 ; \text { plexiglass, } 1.6)
\end{aligned}
$$

Therefore,

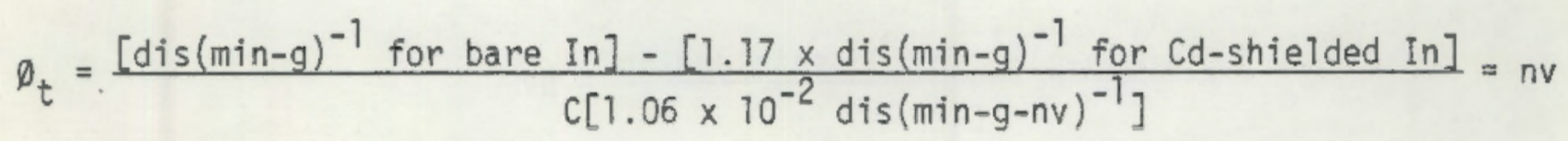

In case the indium foils cannot be counted before their radioactivity has decayed away, a pair of gold foils is provided and serves the same purpose as the indium foils. The gold half life is 2.7 days. No correction is made for the cadmium absorption of the $5-\mathrm{eV}$ resonance neutrons. 
The equation for evaluation of thermal neutron fluence $\left(\theta_{t}\right)$ using gold foils is

$$
\emptyset_{t}=\frac{\left[\operatorname{dis}(\min -g)^{-1} \text { for bare Au }\right]-\left[\operatorname{dis}(\min -g)^{-1} \text { for } \mathrm{Cd} \text {-shielded Au }\right]}{C_{2} C}=n v
$$

where

$$
\begin{aligned}
\operatorname{dis}(\min -g)^{-1}= & \text { corrected value of foil activation as for indium } \\
C_{2}= & 5.3 \times 10^{-5} \operatorname{dis}(\text { min-g-nv })^{-1} \\
C_{=}= & \text {backscatter coefficient for material against which the } \\
& \text { dosimeter is mounted }(9) \text { (air, } 1.0 \text {; human body, 2.0; stain- } \\
& \text { less stee1, } 1.4 ; \text { concrete, } 1.6 ; \text { plexiglass, } 1.6)
\end{aligned}
$$

Therefore,

$$
\emptyset_{t}=\frac{\left[\operatorname{dis}(\min -g)^{-1} \text { for bare Au }\right]-\left[\operatorname{dis}(\min -g)^{-1} \text { for Cd-shielded Au }\right]}{C\left[5.3 \times 10^{-5} \operatorname{dis}(\min -g-n v)^{-1}\right]}=n v
$$

ENERGY RANGE, 0.3 to $2 \mathrm{eV}$

Cadmium-shielded indium becomes activated primarily by neutrons between 0.3 and $2 \mathrm{eV}$. The equation for the epithermal neutron fluence $\left(\emptyset_{e}\right)$ is given by

$$
\varphi_{e}=\frac{\text { dis }(\text { min-g })^{-1} \text { for Cd-shielded In }}{C_{3} C}=n v
$$

where

$$
\begin{aligned}
\operatorname{dis}(\min -\mathrm{g})^{-1}= & \text { corrected value of activation for cadmium-shielded } \\
& \text { indium foil (same value as used in Equation (2)) }
\end{aligned}
$$




$$
\begin{aligned}
C_{3}= & 1.4 \times 10^{-1} \text { dis(min-g-nv) } \\
C= & \text { backscatter coefficient for material against which the } \\
& \text { dosimeter is mounted }(9) \text { (air, } 1.0 \text {; human body, } 2.0 ; \\
& \text { stainless steel, } 1.4 \text {; concrete, } 1.6 \text {; plexiglass, } 1.6)
\end{aligned}
$$

Therefore,

$$
\emptyset_{\mathrm{e}}=\frac{\operatorname{dis}(\min -\mathrm{g})^{-1} \text { for } \mathrm{Cd}-\text { shielded In }}{c\left[1.4 \times 10^{-1} \text { dis }(\text { min-g-nv })^{-1}\right]}=n v
$$

The use of gold to determine the epithermal neutron fluence will give a different result from that given by indium foils because the resonance absorption peak of about $3000 \mathrm{~b}$ lies at $5 \mathrm{eV}$ rather than at $1.4 \mathrm{eV}$ as for indium. The range most effectively covered by gold, therefore, is 0.3 to about $10 \mathrm{eV}$.

The equation for epithermal neutron fluence $\left(\emptyset_{e}\right)$ using a gold foil is

$$
\emptyset_{e}=\frac{\text { dis }(\text { min-g })^{-1} \text { for Cd-shielded Au }}{C_{4} C}=n v
$$

where

$$
\begin{aligned}
\operatorname{dis}(\min -g)^{-1}= & \text { same value as used in thermal fluence calculation for cadmium- } \\
& \text { shielded gold (Equation }(3)) \\
C_{4}= & 1.4 \times 10^{-3} \text { dis(min-g-nv) } \\
C= & \text { backscatter coefficient for material against which the dosi- } \\
& \text { meter is mounted }(9) \text { (air, } 1.0 \text {; human body, } 2.0 \text {; stainless } \\
& \text { steel, } 1.4 \text {; concrete, } 1.6 ; \text { plexiglass, } 1.6)
\end{aligned}
$$

Therefore,

$$
\emptyset_{e}=\frac{\operatorname{dis}(\min -g)^{-1} \text { for } C d-\text { shielded Au }}{c\left[1.4 \times 10^{-3} \operatorname{dis}(\min -g-n v)^{-1}\right]}=n v
$$




\section{ENERGY RANGE, $2 \mathrm{eV}$ to $1 \mathrm{MeV}$}

Copper exhibits an average absorption cross section of $0.090 \mathrm{~b}$ from thermal energies up to about $\mathrm{i} \mathrm{MeV}$, at which point the nonelastic neutron scatter cross section becomes dominating. A $657-\mathrm{keV}$ positron is emitted by $19 \%$ of the $12.8-\mathrm{hr}$ half-1ife ${ }^{64} \mathrm{Cu}$ atoms. The $510-\mathrm{keV}$ positron annihilation gammas are counted. The equation used to calcuiate the intermediate neutron fluence $\left(\phi_{i}\right)$ is given by

$$
\emptyset_{i}=\frac{\operatorname{dis}(\min -g)^{-1} \text { for } C u}{C_{5} c}-2.2 \emptyset_{e}=n v
$$

where

$$
\begin{aligned}
& \operatorname{dis}(\min -g)^{-1}(\mathrm{Cu})=\text { value of activation corrected for background, counting } \\
& \text { geometry, and decay before counting } \\
& c_{5}=1.6 \times 10^{-6} \text { dis (min-g-nv) }{ }^{-1} \\
& C=\text { backscatter coefficient for material against which the } \\
& \text { dosimeter is mounted }{ }^{(g)} \text { (air, 1.0; human body, 2.0; } \\
& \text { stainless steel, 1.4; concrete, 1.6; plexiglass, 1.6) }
\end{aligned}
$$

Therefore,

$$
\emptyset_{i}=\frac{\operatorname{dis}(\min -g)^{-1} \text { for } C u}{c\left[1.6 \times 10^{-6} \operatorname{dis}(\min -g-n v)^{-1}\right]}-2.2 \varphi_{e}=n v
$$

The thermal fluence value need not be subtracted from Equation (6) because the copper is shielded from thermal neutrons by 0.040-in.-thick cadmium.

If the gold foils are used to determine epithermal fluence, then Equation ( $\sigma$ ) covers the range $10 \mathrm{eV}$ to $7 \mathrm{MeV}$. Equation (6) remains the same except that $\emptyset_{e}$ is calculated by Equation (5). 


\section{ENERGY RANGE, 1 to $2.9 \mathrm{MeV}$}

Neutrons in the $1-$ to $2.9-\mathrm{MeV}$ energy range can be measured with an indium foil. Indium-115 has an inelastic neutron scattering threshold at about $450 \mathrm{kev}$. (10) The cross section for the reaction becomes significant at about $1 \mathrm{MeV}$ and is assumed to be an average of $150 \mathrm{mb}$ for a Godiva neutron spectrum.

The inelastic scattering of fast neutrons in ${ }^{115}$ In yields a $4.5-\mathrm{hr}$ halflife isomer that decays by $0.335-\mathrm{MeV}$ gamma and $0.96 \mathrm{-MeV}$ beta emission. The cadmium-shielded indium foil is used to reduce activity interference from thermal neutron absorption. The determination of the neutron fluence between 1 and $2.9 \mathrm{MeV}$ is calculated by the equation

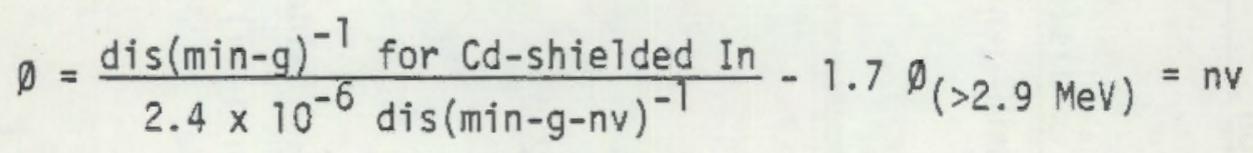

ENERGY RANGE, ABOVE $2.9 \mathrm{MeV}$

Sulfur-32 exhibits a ${ }^{32} \mathrm{~S}(\mathrm{np})^{32} \mathrm{p}$ reaction threshold at about $2.5 \mathrm{MeV}$. The cross section for this reaction becomes significant at about $2.9 \mathrm{MeV}$ and is assumed to be constant at $230 \mathrm{mb}$ above $2.9 \mathrm{MeV}$. The radioactive product of the reaction is ${ }^{32} \mathrm{P}$; by emitting a $1.71-\mathrm{MeV}$ beta particle, it decays with a half life of 14.5 days. The neutron fluence above $2.9 \mathrm{MeV}$ is calculated using the equation

$$
\emptyset=\frac{\operatorname{dis}(\min -g)^{-1} \text { for } S}{1.53 \times 10^{-7} \text { dis }(\text { min-g-nv })^{-1}}=n v
$$

Table 3 summarizes the equations for calculating the neutron spectrum. 
TABLE 3. Equations for Calculating Neutron Fluence

Energy Range

0.025 to $0.3 \mathrm{eV}$

0.3 to $2.0 \mathrm{eV}$

1 to $2.9 \mathrm{MeV}$

$>2.9 \mathrm{MeV}$

\section{Equation}

$\varphi_{t}=\frac{\left[\operatorname{dis}(\min -\mathrm{g})^{-1} \text { for bare } \mathrm{In}\right]-\left[1.17 \times \operatorname{dis}(\min -\mathrm{g})^{-1} \text { for Cd-shielded In }\right]}{C\left[1.06 \times 10^{-2} \operatorname{dis}(\min -\mathrm{g}-\mathrm{nv})^{-1}\right]}$

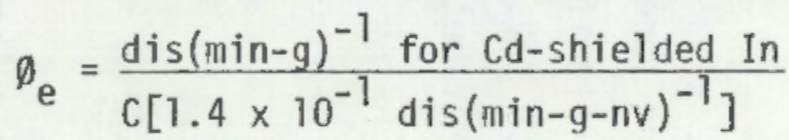

$\sigma$

$2.0 \mathrm{eV}$ to $1 \mathrm{MeV}$

$\emptyset_{i}=\frac{\operatorname{dis}(\min -\mathrm{g})^{-1} \text { for } \mathrm{Cu}}{c\left[1.6 \times 10^{-6} \operatorname{dis}(\min -\mathrm{g}-\mathrm{nv})^{-1}\right]}-2.2 \emptyset_{\mathrm{e}}$

$\emptyset(1.0$ to $2.0 \mathrm{MeV})=\frac{\operatorname{dis}(\text { min-g })^{-1} \text { for Cd-shielded In }}{2.4 \times 10^{-6} \text { dis }(\text { min-g-nv })^{-1}}-1.7 \emptyset(>2.9 \mathrm{MeV})$

$\emptyset_{(>2.9 \mathrm{MeV})}=\frac{\operatorname{dis}(\min -\mathrm{g})^{-1} \text { for } \mathrm{s}}{1.53 \times 10^{-7} \operatorname{dis}(\min -g-n v)^{-1}}$ 


\section{GAMMA DOSIMETRY}

Two ${ }^{7}$ LiF TLD chips are included in the dosimeter packa.ge to measure gamma dose. One chip is placed in the lower aluminum foil holder and measures gamma dose in the center of the paraffin shield. The second chip is placed in the upper foil holder. The TLD chips are calibrated on TLD readers operated by the Physics and Instrumentation Department at Battelle, Pacific Northwest Laboratories. On the calibrated readers the dose (in rads) is calculated by the following equation:

$$
\text { Dose }=\frac{\text { Raw Data from }{ }^{7} \mathrm{LiF}}{1100}
$$

Data indicate that the gamma dose from an unmoderated ${ }^{235} \mathrm{U}$ fission spectrum will be overestimated by $50 \%$ by the ${ }^{7}$ LiF chip in the center of the paraffin shield. However, when the same spectrum is modified by $12 \mathrm{~cm}$ of hydrogenous moderator, the dose from the shielded TLD is the same as the dose measured by the ${ }^{7}$ LiF from the upper foil holder. 


\section{SUMMARY AND CONCLUSIONS}

The Hanford critical radiation dosimeter provides a rapid, accurate, and relatively inexpensive means of determining neutron and gamma radiation exposure dose from a radiation release of accident proportions. An accident is defined as a radiation release of such magnitude that personnel in the vicinity of the release may receive a total absorbed radiation dose in excess of the permissible limits.

The neutron exposure estimation is arrived at rapidly by counting either the gold or TLD chips from the center of the paraffin moderator and performing the calculation shown in Table 2. If the neutron spectrum has not been greatly degraded toward thermal energies, the dose value thus obtained will be accurate to within $\pm 15 \%$.

The extent of degradation of the neutron energy spectrum depends on several factors. The amount and type of shielding material through which the neutrons pass before reaching the dosimeter are important. Shielding materials with a high hydrogen content, such as concrete, paraffin, and water, are usually used when neutron shielding is desired. Moderately thick shields (up to $2 \mathrm{ft}$ ) of these materials can degrade the neutron energy spectrum considerably. A significant portion of the neutron dose received in tissue outside such a shield would, however, be due to fast neutrons. The assumption is that a significant portion ( $90 \%$ or more) of the neutrons are fast (>100 keV) as would be the case for a ${ }^{235} \mathrm{U}$ fission or a Godiva spectrum. Thicker shields (up to 5 or $6 \mathrm{ft}$ ) of the hydrogen-bearing materiais will degrade the neutron energy spectrum to the extent that only a few percent of the tissue dose would be due to fast neutrons. Shields thicker than 5 or $6 \mathrm{ft}$ would essentially thermalize the neutrons, i.e., the tissue dose would be due almost entirely to slow and intermediate neutrons (>100 keV).

In contrast, nonhydrogen-bearing shielding materials commonly used for beta and gamma radiation shielding, such as lead or iron, are relatively poor neutron shields. Although some neutron capture takes place in them, shields of this type are poor neutron moderators; thus, fast neutrons pass through with little reduction of energy. The neutron dose to tissue shielded by 
several feet of lead or iron is, therefore, still attributable primarily to fast neutrons, provided the source neutrons are predominantly fast. The neutron spectrum may even be "hardened" by this type of shieid because of the upward shift of the average energy.

Another source of spectrum degradation is room scatter, which means that neutrons that ordinarily would not be incident on the dosimeter are scattered or reflected to it by objects in the vicinity, a wall, other shielding materials, or air. Because of the nature of scatter phenomena, these scattered neutrons are degraded in energy before reaching the dosimeter.

Analysis of activated foils is accomplished using $\mathrm{Ge}(\mathrm{L} i)$ detectors and associated electronics. Standardized evaluation techniques, including routine calibration checks, are used to ensure the successful long-range performance of the dosimeter system. Thermoluminescent dosimeters are evaluated using a Harshaw model 2000 TLD reader that is also routinely calibrated. 


\section{REFERENCES}

1. P. F. Bramson, Hanford Criticality Dosimeter. HW-71710, General Electric Co., Richland, WA, 1962.

2. J. DePangher, "Double Moderator Neutron Dosimeter." Nuclear Instruments and Methods, 67-74, May 1959.

3. W. N. Ness, Neutrons from $(\alpha, n)$ Sources. UCRL-3839, University of California Radiation Laboratory, Berkeley, CA, July 1957.

4. D. J. Hughes, Pile Neutron Research. Addison-Wesley Publishing Co., Inc., Cambridge, MA, 1953.

5. J. A. Sayeg, Revised Neutron Flux Spectrum and Tissue Dose Measurements at the Godiva II Critical Assembly. LA-2432, Los Alamos Scientific Laboratory, Los Alamos, NM, 1960.

6. L. F. Kocher, G. W. R. Endres, L. L. Nichols, D. B. Shipler and A. J. Haverfield, The Hanford Thermoluminescent Multipurpose Dosimeter. BNWL-SA-3955, Battelle, Pacific Northwest Laboratories, Richland, WA, May 1971.

7. National Bureau of Standards, Protection Against Neutron Radiation Up To 30 Million Electron Volts. National Bureau of Standards Handbook No. 63, Washington, DC, 1957.

8. J. E. Hoy, An Emergency Neutron Dosimeter. DP-472, duPont de Nemours \& Co., Inc., Aiken, SC, 1960.

9. C. W. Tuttle, "Slow Neutron Detection by Foils - I and II." Nucleonics $\underline{8}(6)$, June 1950; $\underline{9}(1)$, July 1951.

10. National Bureau of Standards, Measurement of Neutron Flux and Spectra for Physical and Biological Apolications. National Bureau of Standards Handbook No. 72 , Washington, $D C, 1960$. 


\section{DISTRIBUTION}

No. of

Copies

OFFSITE

1 A. A. Churm

DOE Chicago Patent Group

9800 South Cass Avenue

Argonne, IL 60439

27 DOE Technical Information Center

ONSITE

3 DOE Richland Operations Office

H. E. Ransom

M. W. Tiernan

G. R. Yesberger

1 Rockwell Hanford Operations

S. Marchetti

1 United Nuclear, Inc.

T. E. Dabrowski

1 Westinghouse Hanford Company

G. D. Carpenter

20 Battelle-Northwest
P. E. Bramson (2)
R. D. Glenn (10)
K. R. Heid (2)
Technical Information (5)
Technical Publications 
